\title{
Estimation of the Parameters and Expected Test Time of Exponentiated Weibull Lifetimes Under Type II Progressive Censoring Scheme With Random Removals
}

\author{
Fathy H. Eissa ${ }^{1,3}$, Shuo-Jye $\mathrm{Wu}^{2} \&$ Hamid H. Ahmed ${ }^{1}$ \\ ${ }^{1}$ College of Science \& Arts, King Abdulaziz University, Jeddah, Saudi Arabia \\ ${ }^{2}$ Department of Statistics, Tamkang University, Tamsui, Taiwan \\ ${ }^{3}$ Faculty of Science, Damanhour University, Egypt. E-mail: fhelmykhamis61@ gmail.com, fkhamis@kau.edu.sa \\ Correspondence: Fathy H. Eissa, College of Science\& Arts, King Abdulaziz University, Jeddah, Saudi Arabia.
}

Received: December 23, 2018

Accepted: January 29, 2018 Online Published: February 11, 2019

doi:10.5539/ijsp.v8n2p124

URL: https://doi.org/10.5539/ijsp.v8n2p124

\begin{abstract}
Based on progressive type-II censored sample with random removals, point and interval estimations for the shape parameters of the exponentiated Weibull distribution are discussed. Computational formula for the expected total test time are derived for different situations of sampling plans. This is useful in planning a life test experiment. The efficiency of the estimators are compared in terms of the root mean square error, the variance and the coverage probability of the corresponding confidence intervals. A simulation study is presented for several values of removal probability and different values of failure percentage. Also, numerical applications are conducted to illustrate and compare the usefulness of the different sampling plans in terms of expected test times for different patterns of failure rates.
\end{abstract}

Keywords: progressive type-II censoring, random removals, maximum likelihood estimation, confidence interval, coverage probability, expected test time, exponentiated Weibull model

\section{Introduction}

In reliability tests involving massive numbers of items and in situations where exceptionally large times to failure are expected, the use of censored data is economically more realistic. The procedure of removing good items from the test before the termination of experiment is known as progressive censoring. In a progressive type-II censoring scheme $n$ identical units are placed on a life-test experiment and removals of still operating units are carried out at observed failure times. That is, after the $\mathrm{i}$-th failure some preassigned number $R_{i}(\mathrm{i}=1,2, \ldots, \mathrm{m})$ of surviving units are randomly removed from the test. This process continues until the $\mathrm{m}$-th failure, $\mathrm{t}_{\mathrm{m}}$, is obtained and the remaining $R_{m}=n-\left(m+\sum_{i=1}^{m-1} R_{i}\right)$ units are all removed at the end of the experiment. Therefore, the observed failure times; $\mathrm{t}_{1}, \mathrm{t}_{2}, \ldots, \mathrm{t}_{\mathrm{m}}$ are called progressively type-II censored order statistics. We denote to the set of observed failure-times and survival withdrawn by $\left\{\mathrm{t}_{\mathrm{i}}, \mathrm{R}_{\mathrm{i}}\right\}, \mathrm{i}=1,2, \ldots, \mathrm{m} ; \mathrm{t}_{1}<\mathrm{t}_{2}<\ldots<\mathrm{t}_{\mathrm{m}}$. If $\mathrm{R}_{\mathrm{i}}=0$ for $\mathrm{i}=1,2, \ldots, \mathrm{m}-1$ and $\mathrm{R}_{\mathrm{m}}>0$, then the progressive type-II censored sample reduces to a conventional type-II censored of $t_{1}, t_{2}, \ldots, t_{m}, m<n$. The importance and usefulness of progressive censoring schemes and its applications in industrial life testing and medical survival analysis can be seen by referring to Balakrishnan and Aggarwalla (2000).

In the last two decades, the statistical inferences for various distribution using progressive censored samples get special attention and are studied by several authors among of them, Viveros and Balakrishnan (1994), Balakrishnan and Sandhu (1995), Childs and Balakrishnan (2000), Mousa and Jaheen (2002), (Balakrishnan et al. (2003), Soliman (2005), Basak et al. (2009), Madi and Raqab (2009), Cheng et al. (2010) and Kim et al. (2011). In these studies the value of $R_{i}$ at the time of the ith failure $t_{i}$ are fixed and preassigned. In practical situations, $R_{i}$ may occur at random. As an example, in some reliability studies in industerial field, an experimenter may decide that it is inapproperiate or too dangerous to carry on the test on some of the tested units even though these units have not failed completely. The number of patients drop out from a clinical test at each stage is random and cannot be prefixed, as another example (See Tse et al. (2000)). In such cases, the experimenter may need to change the censoring numbers during the experiment and so adaptation process of progressive censoring scheme is needed. $\mathrm{Ng}$ et al. (2009) proposed an adaptive censoring scheme in which the censoring scheme $\left(R_{1}, R_{2}, \ldots, R_{m}\right)$ may change during the experiment according to a prefixed threshold time $T>0$ to keep the effective sample size $\mathrm{m}$ of failures. Before the time $\mathrm{T}$ the conventional progressive censoring scheme is applied. 
After passing time $\mathrm{T}$ withdrawing surviving units is stopped at all until the time of mth failure where all remaining surviving units are removed. Yuen and Tse (1996) proposed progressive censoring scheme in which the number $R_{j}$ of units removed at each failure is random and is chosen according to a probability distribution with support $\{0, \ldots, \mathrm{n}-\mathrm{m}\}$ and the prbability mass function of this distribution is independent of failure time. Recently, some authors have discussed inference problem for various distribution when the data are progressively censored with random removals, among of them: Tse et al. (2000), Wu and chang (2003), Wu et al. (2007), Sarhan et al. (2008) and Kumar et al. (2016).

The purpose of this paper is concerned with inferences using progressively type-II censored data with random removals from exponentiated Weibull distribution.The probability density functon, cumulative distribution function, and reliability function of this distribution are, respectively,

$$
f(t)=\alpha \theta t^{\alpha-1} e^{-t^{\alpha}}\left(1-e^{-t^{\alpha}}\right)^{\theta-1}, \mathrm{t}>0 ; \alpha, \theta>0
$$

and

where $\alpha$ and $\theta$ are the two shape parameters.

$$
F(t)=\left(1-e^{-t^{\alpha}}\right)^{\theta}
$$

This distribution is an extension of the well known Weibull distribution. It accommodates unimodal, bathub-shaped and broader classes of monotone failure rates. Mudholkar et al. (1995) showed that, for the exponentiated Weibull distribution, the failure rate is (a) unimodal for $\alpha<1$ and $\alpha \theta>1$, (b) bathtub-shaped for $\alpha>1$ and $\alpha \theta<1$, (c) decreasing for $\alpha \leq 1$ and $\alpha \theta \leq 1$, and (d) increasing for $\alpha \geq 1$ and $\alpha \theta \geq 1$. In practice, the exponentiated Weibull distribution as a failure model is more realistic than that of monotone failure rates and plays an important role to represent several lifetime data that are of bathtub-shaped or upside-down bathtub shape failure rates. The distribution includes exponential, generalized exponential, Burr type X and reyligh sub-models. See Mudholkar and Hutson (1996) and Nassar and Eissa (2003). However, The exponentiated Weibull distribution as a failure model gives a good idea about using the progressive censoring schemes with random removals.

The rest of this paper is organized as follows: Section 2 presents the model under consideration and the likelihood function of the model parameters.Section 3 derives the maximum likelihood equations and discusses the asymptotic properties of the maximum likelihood estimators (MLEs). Also, the confidence intervals of $\alpha$ and $\theta$ are obtained. In Section 4, simulation results is made to assess the performance of the estimators. Analytical formulas for expected test time are derived in Section 5. Numerical analyses for the expected test time are presented in Section 6.

\section{Model}

Suppose a progressive type-II censored sample $\left\{t_{i}, R_{i}\right\}, i=1,2, \ldots, m$, is obtained when $n$ units are put on a life test terminated at prespcified number $\mathrm{m}(\leq \mathrm{n})$ of failures are observed. The number of surviving units that are removed from the test at the ith failure, $\mathrm{R}_{\mathrm{i}}$, is a random variable. The sample of failure times are considered to have an exponentiated Weibull distribution with density and distribution functions given, respectively, by equations (1) and (2). Let $R_{1}=r_{1}$, $R_{2}=r_{2}, \ldots, R_{m}=r_{m}$ and denote the set of lifetimes $\underline{t}=\left\{t_{1}, t_{2}, \ldots, t_{m}\right\}$ and $\underline{r}=\left\{r_{1}, r_{2}, \ldots, r_{m}\right\}$, say. The conditional likelihood function defined by Cohen (1963) is

$$
\mathrm{L}(\alpha, \theta ; \underline{\mathrm{t}} \mid \mathrm{R}=\underline{\mathrm{r}})=\mathrm{C} \prod_{\mathrm{i}=1}^{\mathrm{m}} \mathrm{f}\left(\mathrm{t}_{\mathrm{i}}\right)\left[1-\mathrm{F}\left(\mathrm{t}_{\mathrm{i}}\right)\right]^{\mathrm{r}_{\mathrm{i}}} .
$$

For progressive type-II censoring with predetermined R's and applying equations (1) and (2) the likelihood function can be obtained as

$$
L_{1}(\alpha, \theta ; \underline{t} \mid R=\underline{r})=C \alpha^{m} \theta^{m} e^{-T},
$$

where $\mathrm{C}=\prod_{i=1}^{m}\left(n-i+1-\sum_{j=0}^{i-1} r_{j}\right), r_{0}=0$,

$$
\begin{aligned}
& \mathrm{T}=\sum_{i=0}^{m}\left\{t_{i}^{\alpha}-(\alpha-1) \ln t_{i}-(\theta-1) \ln u_{i}-r_{i} \ln \left(1-u_{i}^{\theta}\right)\right\}, \\
& u_{i}=u_{i}(\alpha)=1-e^{-t_{i}^{\alpha}} \text { and } 0 \leq r_{i} \leq n-m-\left(r_{1}+r_{2}+\ldots+r_{i-1}\right) .
\end{aligned}
$$

The form of equation (4) is conditional on $r_{i}$. We consider the case of progressive type-II censoring in which $R_{i}$ is independent of $T_{i}$ for all $i$ and is assumed to follow a binomial distribution with parameters n-m- $\sum_{j=1}^{i-1} r_{j}$ and $p$. The parameter $p$ is the probability of removal of each unit and is assumed to be the same for all removals. Therefore, we have

$$
\begin{gathered}
\mathrm{P}\left(R_{1}=r_{1}\right)=\left(\begin{array}{c}
n-m \\
r_{1}
\end{array}\right) p^{r_{1}}(1-p)^{n-m-r_{1}}, \\
\mathrm{P}\left(R_{2}=r_{2} \mid R_{1}=r_{1}\right)=\left(\begin{array}{c}
n-m-r_{1} \\
r_{2}
\end{array}\right) p^{r_{2}}(1-p)^{n-m-r_{1}-r_{2}}, \ldots, \\
\mathrm{P}\left(R_{i}=r_{i} \mid R_{i-1}=r_{i-1}, \ldots, R_{1}=r_{1}\right)=
\end{gathered}
$$




$$
\left(\begin{array}{c}
n-m-\sum_{j=0}^{i-1} r_{j} \\
r_{i}
\end{array}\right) p^{r_{i}}(1-p)^{n-m-\sum_{j=1}^{i-1} r_{j}} .
$$

where $0 \leq r_{i} \leq n-m-\sum_{j=1}^{i-1} r_{j}, i=1,2, \ldots, m-1$.

Since the random mechanism producing the removals is independent of the data, i.e. $R_{i}$ is independent of lifetimes for all $\mathrm{i}$, the likelihood function can be written as

$$
\mathrm{L}_{2}(\alpha, \theta, \mathrm{p} ; \underline{\mathrm{t}}, \underline{\mathrm{r}})=\mathrm{L}_{1}(\alpha, \theta ; \underline{\mathrm{t}} \mid \mathrm{R}=\underline{\mathrm{r}}) \mathrm{P}(\mathrm{R}, p)
$$

where the second term in the right hand side of equation (7), is

$$
\begin{array}{r}
\mathrm{P}(\mathrm{R}, p)=\mathrm{P}\left(\mathrm{R}_{1}=\mathrm{r}_{1}\right) \mathrm{P}\left(\mathrm{R}_{2}=\mathrm{r}_{2} \mid \mathrm{R}_{1}=\mathrm{r}_{1}\right) \mathrm{P}\left(\mathrm{R}_{3}=\mathrm{r}_{3} \mid \mathrm{R}_{2}=\mathrm{r}_{2}, \mathrm{R}_{1}=\mathrm{r}_{1}\right) \\
\ldots \mathrm{P}\left(\mathrm{R}_{\mathrm{m}-1}=\mathrm{r}_{\mathrm{m}-1} \mid \mathrm{R}_{\mathrm{m}-2}=\mathrm{r}_{\mathrm{m}-2}, \ldots, \mathrm{R}_{1}=\mathrm{r}_{1}\right)
\end{array}
$$

Substituting the forms of equation (6) in equation (8), we get

$$
\mathrm{P}(\mathrm{R}, p)=\frac{(\mathrm{n}-\mathrm{m}) !}{\left(\mathrm{n}-\mathrm{m}-\sum_{\mathrm{j}=1}^{\mathrm{i}-1} \mathrm{r}_{\mathrm{j}}\right) ! \prod_{\mathrm{i}=1}^{\mathrm{m}-1}\left(\mathrm{r}_{\mathrm{i}} !\right)} p^{\mathrm{C} 1}(1-p)^{\mathrm{C} 2}
$$

where $\mathrm{C} 1=\sum_{i=1}^{m-1} r_{i}$ and $\mathrm{C} 2=(m-1)(n-m)-\sum_{i=1}^{m-1}(m-i) r_{i}$.

\section{Maximum Likelihood Estimation}

In this section, we will derive the MLEs of $\alpha$ and $\theta$. It is clear that the joint probability distribution of R's does not involve the parameters $\alpha$ and $\theta$. The MLEs $\hat{\alpha}$ and $\hat{\theta}$ of $\alpha$ and $\theta$, respectively, can be obtained directly by maximizing the function $\mathrm{L}_{1}(\alpha, \theta ; \underline{t} \mid R=\underline{r})$ given by equation (4). The log-likelihood function, $\ln \mathrm{L}_{1}(\alpha, \theta ; \underline{t} \mid R=\underline{r})=$ $l(\alpha, \theta)$, is

$l(\alpha, \theta)=C+m \ln \alpha+m \ln \theta-T$.

The maximum likelihood estimators $\widehat{\alpha}$ and $\hat{\theta}$ are the values that solves the first order conditions

$$
\begin{gathered}
\frac{\partial l(\alpha, \theta)}{\partial \theta}=\frac{m}{\theta}-T_{1}=0 \\
\frac{\partial l(\alpha, \theta)}{\partial \alpha}=\frac{m}{\alpha}-T_{2}-\theta T_{3}-T_{4}=0 .
\end{gathered}
$$

where $T_{1}=\sum_{i=1}^{m} \zeta_{i} \ln u_{i}, \quad T_{2}=\sum_{i=1}^{m}\left(t_{i}^{\alpha}-1\right) \ln t_{i}$,

$$
\begin{aligned}
& T_{3}=\sum_{i=1}^{m} \zeta_{i} \eta_{i} \ln t_{i}, T_{4}=\sum_{i=1}^{m} \eta_{i} \ln t_{i} \\
& \zeta_{i}=r_{i} U_{i}-1, \quad U_{i}=\left(u_{i}^{-\theta}-1\right)^{-1}, \quad u_{i}=1-e^{-t_{i}^{\alpha}}
\end{aligned}
$$

and $\eta_{i}=u_{i}^{-1} t_{i}^{\alpha} e^{-t_{i}^{\alpha}}$

Equations (10) gives the necessary conditions for a maximum. In addition, the Hessian matrix, $H(\gamma)$, of the exponentiated Weibull log-likelihood function is

$H(\gamma)=\left(a_{i j}\right)=\left(\frac{\partial^{2} l(\alpha, \theta)}{\partial \gamma_{i} \partial \gamma_{j}}\right), i, j=1,2, \gamma=(\alpha, \theta)$.

The elements $a_{i j}, i, j=1,2$ are given by

$$
\begin{gathered}
a_{22}=-\frac{m}{\theta^{2}}-\sum_{i=1}^{m} \xi_{i}\left(\ln u_{i}\right)^{2}, \\
a_{11}=-\frac{m}{\alpha^{2}}-\sum_{i=1}^{m} t_{i}^{\alpha}\left(\ln t_{i}\right)^{2}-\sum_{i=1}^{m}\left(\theta^{2} \xi_{i}-\theta \zeta_{i}-1\right) \eta_{i}{ }^{2}\left(\ln t_{i}\right)^{2} \\
-\sum_{i=1}^{m}\left(\theta \zeta_{i}+1\right)\left(1-t_{i}^{\alpha}\right) \eta_{i}\left(\ln t_{i}\right)^{2}, \\
a_{12}=a_{21}=-\theta \sum_{i=1}^{m} \xi_{i} \eta_{i} \ln u_{i} \ln t_{i}-T_{3}
\end{gathered}
$$

where $\xi_{i}=r_{i} U_{i}\left(1+U_{i}\right)$. It easy to see that $a_{11}, a_{22}$ and $a_{12}$ are all negative where the terms $\zeta_{i}<0$, $\xi_{i}>0$, $\eta_{i}>0$ and $T_{3}>0$ for $\alpha>0$ and $\theta>0$ as well as $\ln u_{i}<0$ and $\ln t_{i}$ can be positive or negative according to $t_{i}$ is greater or less than one. Fluctuating values of $\ln t_{i}$ between positive and negative does not affect on the ultimate value of the $a_{11}, a_{22}$ and $a_{12}$ to be negative. Therefore, the Hessian matrix of the log-likelihood function $1(\alpha, \theta)$ is negative definite at every value of $\alpha>0$ and $\theta>0$. We can say that $1(\alpha, \theta)$ is strictly concave and hence any local 
maximizer that we find will be the unique global maximizer, i.e. the estimated parameters $\hat{\alpha}$ and $\hat{\theta}$ solving the first-order conditions given by equations (10) are the unique maximum likelihood solution. At this point, we conclude that the system of likelihood equations (10) admits a unique solution in the region $R^{+} \times R^{+}$and that the $\log$-likelihood function $1(\alpha, \theta)$ is strictly concave but we can not say that this system always has a unique solution. The conditions, by which the solutions are always exist, need further and deep discussion in other work. Now, searching about a solution $(\widehat{\alpha}, \hat{\theta})$ of equations (10) at which the Hessian matrix is negative definite must be cosidered. It is difficult to obtain such solution (analytically) in closed form. Thus we resort to obtain the solution by using an iterative technique. For more details about the existence and uniqueness of maximum likelihood estimates, see Makelainen et al. (1981).

To evaluate the performance of the estimators and studying the variation of the MLEs of the parameters of our lifetime distribution, the asymptotic variances and covariances of $\hat{\alpha}$ and $\hat{\theta}$ are obtained. It is clear that $p$ is only a parameter of binomial removal distribution and does not provide information about the lifetime distribution. On the basis of the asymptotic normality property of the tow-dimentional ML estimators, the asymptotic distribution of the vector $\sqrt{n}(\hat{\alpha}-\alpha \hat{\theta}-\theta)^{T}$ approaches $N\left(0, I^{-1}\right)$ as $\mathrm{n}$ approaches infinity and for large value of effective sample size $\mathrm{m}$, $\mathrm{m}<\mathrm{n}$ (See Ng et. al. (2009), Rao (1973), and Mood et. al. (1974)). The Fisher information matrix $I=I(\alpha, \theta)$ is associated with the parameters $\alpha$ and $\theta$. Using the observed information, we evaluate the approximate variance-covariance matrix, $\left(\mathrm{C}_{\mathrm{ij}}\right)$, say,

The elements $v_{i j}$ can be obtained as follows:

$$
\left(C_{i j}\right)=\left(v_{i j}\right)^{-1}, i, j=1,2 .
$$

$$
\begin{gathered}
\mathrm{v}_{11}=\frac{\mathrm{m}}{\alpha^{2}}+\sum_{\mathrm{i}=1}^{\mathrm{m}} \mathrm{t}_{\mathrm{i}}^{\alpha}\left(\ln \mathrm{t}_{\mathrm{i}}\right)^{2}+\sum_{\mathrm{i}=1}^{\mathrm{m}}\left(\xi_{\mathrm{i}} \theta^{2}-\zeta_{\mathrm{i}} \theta-1\right) \eta_{\mathrm{i}}^{2}\left(\ln t_{i}\right)^{2}+\sum_{\mathrm{i}=1}^{\mathrm{m}}\left(\zeta_{\mathrm{i}} \theta+1\right)\left(1-\mathrm{t}_{\mathrm{i}}^{\alpha}\right) \eta_{\mathrm{i}}\left(\ln t_{i}\right)^{2}, \\
\mathrm{v}_{22}=\frac{\mathrm{m}}{\theta^{2}}+\sum_{\mathrm{i}=1}^{\mathrm{m}} \xi_{\mathrm{i}}\left(\ln \mathrm{u}_{\mathrm{i}}\right)^{2}, \quad \text { and } \mathrm{v}_{12}=\mathrm{v}_{21}=\theta \sum_{i=1}^{m} \xi_{i} \eta_{i} \ln u_{i} \ln t_{i}+T_{3}
\end{gathered}
$$

where $\xi_{i}=r_{i} U_{i}\left(1+U_{i}\right) ; \zeta_{i}$ and $\eta_{i}$ are given in equation (10).

Computing the values of the elements given by equations (12) at the estimated values $\hat{\alpha}$ and $\hat{\theta}$ we get

$$
\operatorname{Var}(\hat{\alpha})=\frac{\widehat{\widehat{V}}_{22}}{\mathrm{D}}, \operatorname{Var}(\hat{\theta})=\frac{\widehat{\mathrm{v}}_{11}}{\mathrm{D}} \text { and } \operatorname{Cov}(\hat{\alpha}, \hat{\theta})=\frac{-\widehat{\mathrm{v}}_{12}}{\mathrm{D}}
$$

where $\mathrm{D}=\hat{\mathrm{v}}_{11} \hat{\mathrm{v}}_{22}-\hat{\mathrm{v}}_{12}^{2}$.

The approximate $100(1-\tau) \%$ confidence intervals (CIs) for the parametrs $\alpha$ and $\theta$ from proressively type II censored data with binomial removals are respectively given by

$$
\left(\hat{\alpha} \pm z_{\tau / 2} \sqrt{\operatorname{Var}(\hat{\alpha})}\right) \text { and } \quad\left(\hat{\theta} \pm z_{\tau / 2} \sqrt{\operatorname{Var}(\hat{\theta})}\right)
$$

where $z_{\tau / 2}$ is the $(1-\tau / 2)$ quantile of the standard normal distribution.

\section{Simulation Results}

We derive, in the above Section, the ML estimators and CIs for the two shape parameters $\alpha$ and $\theta$ of the exponentiated Weibull distribution. The likelihood equations (10) are solved, numerically. In order to assess the statistical performances of these estimators under progressive type-II censored sample with random removals, a simulation study is conducted by using generated random samples of different sizes. Samples were generated from exponentiated Weibull distribution with $\alpha=0.8(\alpha<1)$ and $\theta=1.7(\alpha \theta>1)$ (unimodal failure rate case). One thousand samples are generated by applying the algorithm of Balakrishnan and Sandhu (1995). Different values of removal probability $p$ and failure percentage (denoted by) $\mathrm{Fp}$, are considered where $\mathrm{Fp}=(m / n) \%$. We employ MATHEMATICA7 program to perform the computations. For different sample sizes, $\mathrm{n}=20$ (small), 30 (moderate), 50 (large), different values of removal probability, $p=0.01,0.05,0.10,0.25$ and 0.50 and different failure-percentages, $\mathrm{Fp}=50 \%, 60 \%, 70 \%$ and $80 \%$, the results are presented in Tables 1-3. The results based on 1000 replications include the root mean square error (RMSE), the mean width of confidence interval, and the average coverage probability (CAP) for each parameter at $\tau=0.05$.

We discuss in light of the results presented in Tables 1-3 how the estimates affected by censoring schemes in our case of all surviving units are randomly removed from the experiment. The removals are binomially distributed with probability $p$.

Our observations about the results are sumerized in the following points: 
1. The RMSEs of $\widehat{\alpha}$ and $\hat{\theta}$ decrease as Fp increases for all sample sizes. This is due to large Fp would imply relatively more failure times being observed, more information about the life times distribution are available and so more efficient estimation of the parameters under consideration. The effect of the removal probability $p$ is also important to decrease the RMSEs of $\widehat{\alpha}$ and $\hat{\theta}$. For a fixed Fp, as the $p$ increases, the RMSEs of these estimators reduce appreciably, specially for small and moderate sample sizes. This means that more withdrawals should be occurred during (not at the end of) the test experiment. The results also reveal that, even for small sample size, the perfomance of ML estimators $\widehat{\alpha}$ and $\hat{\theta}$ improve in terms of their variances for increasing $p$. The RMSEs and variances are decreasing, as a rule, from table to table as the sample sizes increase.

2- The mean width of the CIs for $\alpha$ and $\theta$ decrease when Fp increases. For a fixed Fp, the mean-width of CIs for $\alpha$ are typically decreasing when $p$ increases for all sample sizes; whilst $\hat{\theta}$ is relatively severe in decreasing of reduction of its mean-width of CIs. The effect of $p$ on the coverage probability, CAP, of the CIs is evident. For small sample size, increasing of $p$ improves the coverage probability to be satiafactory at $\mathrm{Fp}=50 \%$ and $60 \%$ and at $\mathrm{Fp}=50 \%$ for moderate sample size. The coverage probabilities are much upper than the nominal level at Fp>60\% and/or increasing $p$ for all sample sizes. We considered other values of failure percentages and the results are not reported since they have a similar pattern to the cases listed in Tables 1-3. Other values of the distribution parameters: $\alpha=0.8(\alpha<1)$ and $\theta=0.75$ $(\alpha \theta<1)$ (decreasing failure rate case), were also considered and the results are not reported since they have a similar pattern to the cases listed in Tables 1-3.

Table 1. RMSEs, variances and average width of CIs and their coverage probabilities (CAP) for MLEs $\hat{\alpha}$ and $\hat{\theta}$ for different values of $\mathrm{Fp}$ and $p$ at $\mathrm{n}=20$

\begin{tabular}{|c|c|c|c|c|c|c|c|c|c|}
\hline \multirow[b]{3}{*}{$\mathrm{Fp}$} & \multirow[b]{3}{*}{$p$} & \multicolumn{8}{|c|}{$\mathrm{n}=20$} \\
\hline & & \multicolumn{4}{|c|}{$\hat{\alpha}$} & \multicolumn{4}{|c|}{$\hat{\theta}$} \\
\hline & & RMSE & Var. & Width & CAP & RMSE & Var. & Width & CAP \\
\hline \multirow{7}{*}{$50 \%$} & 0.01 & 1.652 & 0.485 & 1.957 & 73.5 & 0.611 & 0.563 & 2.190 & 86.0 \\
\hline & 0.05 & 1.536 & 0.375 & 1.775 & 71.4 & 0.605 & 0.480 & 2.085 & 85.2 \\
\hline & 0.10 & 1.336 & 0.276 & 1.548 & 76.8 & 0.605 & 0.512 & 2.174 & 86.5 \\
\hline & 0.25 & 0.903 & 0.142 & 1.194 & 90.8 & 0.560 & 0.449 & 2.177 & 91.2 \\
\hline & 0.50 & 0.794 & 0.109 & 1.034 & 91.7 & 0.561 & 0.423 & 2.128 & 91.4 \\
\hline & 0.75 & 0.406 & 0.066 & 0.873 & 97.6 & 0.539 & 0.367 & 2.115 & 94.4 \\
\hline & 0.90 & 0.388 & 0.055 & 0.831 & 97.9 & 0.563 & 0.354 & 2.150 & 95.3 \\
\hline \multirow{5}{*}{$60 \%$} & 0.01 & 0.862 & 0.227 & 1.326 & 90.4 & 0.569 & 0.499 & 2.044 & 92.2 \\
\hline & 0.05 & 0.742 & 0.153 & 1.194 & 91.4 & 0.543 & 0.409 & 2.024 & 92.7 \\
\hline & 0.10 & 0.574 & 0.104 & 1.039 & 94.7 & 0.533 & 0.381 & 2.034 & 93.6 \\
\hline & 0.25 & 0.552 & 0.083 & 0.950 & 95.0 & 0.518 & 0.324 & 1.942 & 93.8 \\
\hline & 0.50 & 0.306 & 0.050 & 0.762 & 98.7 & 0.518 & 0.310 & 1.988 & 97.4 \\
\hline \multirow{5}{*}{$70 \%$} & 0.01 & 0.441 & 0.078 & 0.914 & 97.0 & 0.516 & 0.317 & 1.877 & 96.6 \\
\hline & 0.05 & 0.395 & 0.067 & 0.858 & 98.0 & 0.477 & 0.289 & 1.839 & 97.4 \\
\hline & 0.10 & 0.329 & 0.059 & 0.855 & 98.0 & 0.471 & 0.265 & 1.861 & 97.5 \\
\hline & 0.25 & 0.258 & 0.041 & 0.717 & 98.6 & 0.469 & 0.256 & 1.830 & 97.6 \\
\hline & 0.50 & 0.234 & 0.035 & 0.678 & 99.4 & 0.480 & 0.248 & 1.846 & 98.6 \\
\hline \multirow{5}{*}{$80 \%$} & 0.01 & 0.357 & 0.043 & 0.753 & 98.8 & 0.475 & 0.239 & 1.801 & 98.3 \\
\hline & 0.05 & 0.236 & 0.036 & 0.678 & 99.1 & 0.466 & 0.226 & 1.737 & 98.3 \\
\hline & 0.10 & 0.214 & 0.031 & 0.653 & 99.6 & 0.462 & 0.218 & 1.764 & 98.8 \\
\hline & 0.25 & 0.208 & 0.027 & 0.618 & 99.9 & 0.473 & 0.213 & 1.768 & 99.8 \\
\hline & 0.50 & 0.208 & 0.027 & 0.628 & 99.9 & 0.467 & 0.208 & 1.758 & 99.6 \\
\hline
\end{tabular}


Table 2. RMSEs, variances and average width of CIs and their coverage probabilities (CAP) for MLEs $\widehat{\alpha}$ and $\hat{\theta}$ for different values of $\mathrm{Fp}$ and $\mathrm{p}$ at $\mathrm{n}=30$

\begin{tabular}{|c|c|c|c|c|c|c|c|c|c|}
\hline \multirow[b]{3}{*}{$\mathrm{Fp}$} & \multirow[b]{3}{*}{$p$} & \multicolumn{8}{|c|}{$\mathrm{n}=30$} \\
\hline & & \multicolumn{4}{|c|}{$\hat{\alpha}$} & \multicolumn{4}{|c|}{$\hat{\theta}$} \\
\hline & & RMSE & Var. & Width & CAP & RMSE & Var. & Width & CAP \\
\hline \multirow{5}{*}{$50 \%$} & 0.01 & 0.852 & 0.278 & 1.438 & 85.1 & 0.481 & 0.468 & 1.901 & 90.3 \\
\hline & 0.05 & 0.646 & 0.159 & 1.193 & 91.3 & 0.452 & 0.358 & 1.813 & 93.2 \\
\hline & 0.10 & 0.364 & 0.087 & 0.967 & 95.6 & 0.434 & 0.283 & 1.765 & 95.9 \\
\hline & 0.25 & 0.277 & 0.056 & 0.779 & 97.6 & 0.421 & 0.259 & 1.713 & 96.5 \\
\hline & 0.50 & 0.190 & 0.034 & 0.669 & 98.8 & 0.395 & 0.209 & 1.685 & 98.3 \\
\hline \multirow{5}{*}{$60 \%$} & 0.01 & 0.612 & 0.094 & 1.005 & 95.0 & 0.431 & 0.242 & 1.638 & 96.1 \\
\hline & 0.05 & 0.339 & 0.060 & 0.869 & 96.9 & 0.427 & 0.209 & 1.637 & 97.6 \\
\hline & 0.10 & 0.261 & 0.046 & 0.755 & 99.7 & 0.396 & 0.199 & 1.583 & 98.8 \\
\hline & 0.25 & 0.199 & 0.027 & 0.611 & 99.6 & 0.397 & 0.174 & 1.578 & 98.8 \\
\hline & 0.50 & 0.172 & 0.024 & 0.575 & 99.6 & 0.394 & 0.171 & 1.573 & 99.3 \\
\hline \multirow{5}{*}{$70 \%$} & 0.01 & 0.242 & 0.046 & 0.738 & 98.6 & 0.388 & 0.179 & 1.490 & 98.7 \\
\hline & 0.05 & 0.214 & 0.036 & 0.687 & 99.4 & 0.383 & 0.160 & 1.468 & 99.3 \\
\hline & 0.10 & 0.199 & 0.027 & 0.617 & 99.8 & 0.380 & 0.151 & 1.480 & 99.8 \\
\hline & 0.25 & 0.175 & 0.020 & 0.542 & 99.9 & 0.374 & 0.145 & 1.470 & 99.7 \\
\hline & 0.50 & 0.154 & 0.018 & 0.512 & 100 & 0.378 & 0.147 & 1.492 & 100 \\
\hline \multirow{5}{*}{$80 \%$} & 0.01 & 0.184 & 0.023 & 0.576 & 99.8 & 0.368 & 0.132 & 1.397 & 99.8 \\
\hline & 0.05 & 0.160 & 0.019 & 0.531 & 99.6 & 0.367 & 0.129 & 1.388 & 99.6 \\
\hline & 0.10 & 0.149 & 0.016 & 0.484 & 100 & 0.362 & 0.128 & 1.394 & 99.9 \\
\hline & 0.25 & 0.145 & 0.016 & 0.487 & 100 & 0.363 & 0.129 & 1.397 & 99.9 \\
\hline & 0.50 & 0.139 & 0.015 & 0.477 & 100 & 0.376 & 0.133 & 1.425 & 100 \\
\hline
\end{tabular}

Table 3. RMSEs, variances and average width of CIs and their coverage probabilities (CAP) for MLEs $\hat{\alpha}$ and $\hat{\theta}$ for different values of Fp and $p$ at $\mathrm{n}=50$

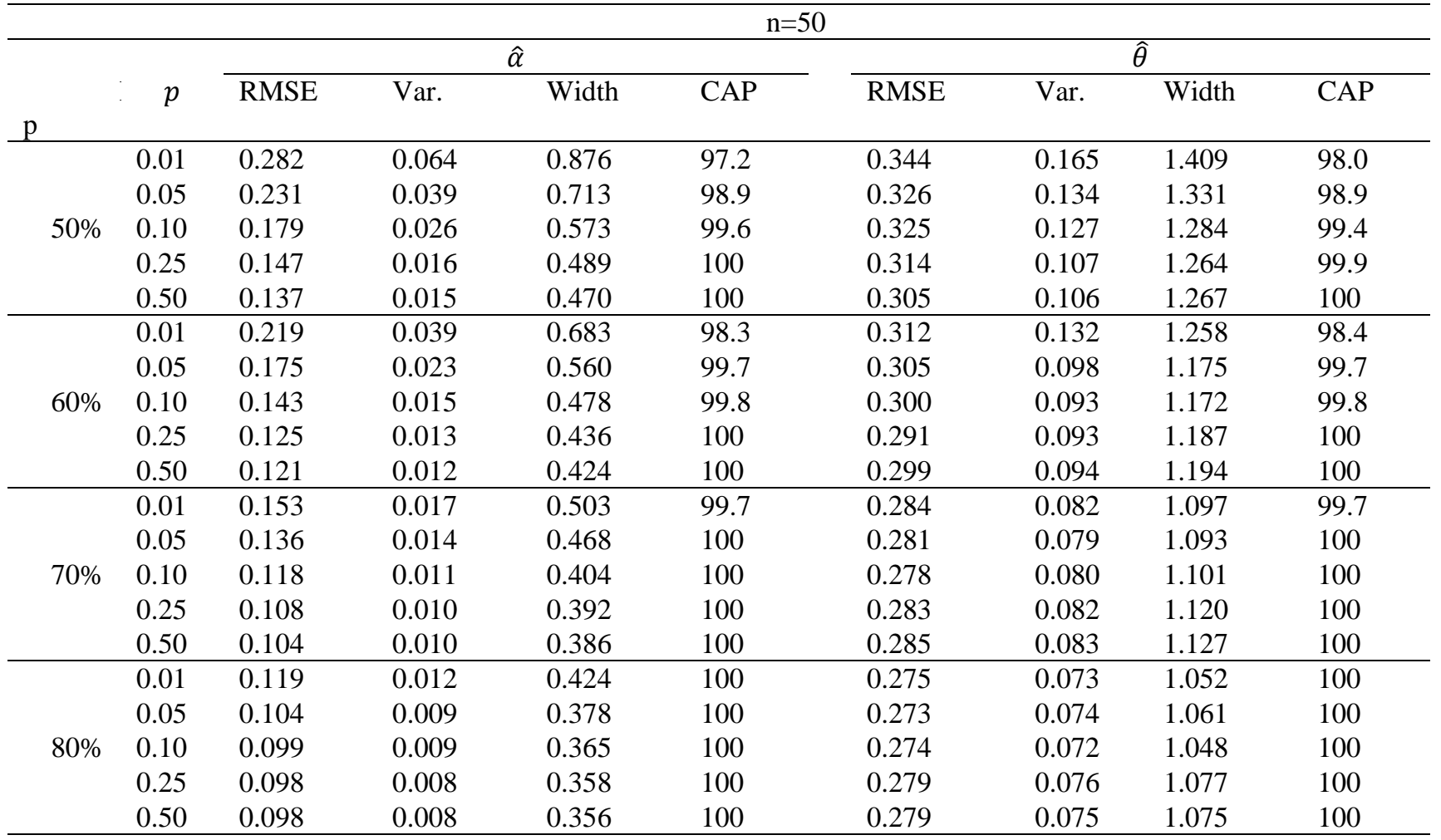

\section{Expicted Test Time}

The expected time of a life test is the expected time required to complete the test experiment. In practice, an experimenter may have aim to explore the time duration of his experiment to choose an approperiate sampling plan. The cost and the time duration to complete a test experiment are related. In the following we derived the expected test time when the data come from exponentiated Weibull distribution for some csaes of sampling schemes. 
In case of complete sample test, the required time to complete the test is the time at the nth, $\mathrm{T}_{\mathrm{n}}$, failure in a sample of $\mathrm{n}$ test units. The expected value of $\mathrm{T}_{\mathrm{n}}$ to observe the nth failure in this sample is given by

In our case, $E\left(T_{n}\right)$ is given by

$$
E\left(T_{n}\right)=n \int_{0}^{\infty} t f(t) F^{n-1}(t) d t .
$$

$$
E\left(T_{n}\right)=n \alpha \theta \int_{0}^{\infty} t^{\alpha} e^{-t^{\alpha}}\left(1-e^{-t^{\alpha}}\right)^{n \theta-1} d t .
$$

Now, for any real number $a$, we have the expansion, (See J. Stewart; page 742),

$$
(1-x)^{a}=\sum_{i=0}^{\infty}(-1)^{i}\left(\begin{array}{c}
a \\
i
\end{array}\right) x^{i}
$$

where $\left(\begin{array}{l}a \\ i\end{array}\right)=\frac{a(a-1)(a-2) \ldots(a-i+1)}{i !}$.

This series always converges when $|x|<1$ as well as it converges at the end points \pm 1 if $a \geq 0$. If a is positive integer the series reduces to the Binomial Theorem and then the last term of the expansion is at $i=a$. Applying the form (16) to the term $\left(1-\mathrm{e}^{-\mathrm{t}^{\alpha}}\right)^{\mathrm{n} \theta-1}, \mathrm{E}\left(\mathrm{T}_{\mathrm{n}}\right)$ given by equation (15) can take the form

$$
\mathrm{E}\left(T_{n}\right)=\mathrm{n} \theta \Gamma\left(\frac{1}{\alpha}+1\right) \sum_{\mathrm{i}=0}^{\infty}(-1)^{\mathrm{i}}\left(\begin{array}{c}
n \theta-1 \\
i
\end{array}\right)(i+1)^{-\left(\frac{1}{\alpha}+1\right)} .
$$

In case of type-II censoring sampling test, The density function of the $\mathrm{m}$-th oredr statistics is

$f\left(t_{m}\right)=m\left(\begin{array}{c}n \\ m\end{array}\right) f(t) F^{m-1}(t)[1-F(t)]^{n-m}$.

The expected time, $\mathrm{E}\left(T_{m}^{*}\right)$, of type II censoring test can be derived as

$$
\mathrm{E}\left(T_{m}^{*}\right)=m\left(\begin{array}{c}
n \\
m
\end{array}\right) \theta \Gamma\left(\frac{1}{\alpha}+1\right) \times
$$

$$
\sum_{j=0}^{n-m}(-1)^{j}\left(\begin{array}{c}
n-m \\
j
\end{array}\right) \sum_{i=0}^{\infty}(-1)^{i}\left(\begin{array}{c}
(m+j) \theta-1 \\
i
\end{array}\right)(i+1)^{-\left(\frac{1}{\alpha}+1\right)}
$$

When $m=n$ we get the expected time of test of complete sampling.

Similarly, under the case of progressive type-II censoring with a fixed number of removals, the expected time required to completean experiment is dfined as the expected value of $T_{m}$ conditioning on $\mathrm{R}$, and given as follows:

$$
\mathrm{E}\left(T_{m} \mid R\right)=\mathrm{C}(\mathrm{r}) \sum_{s_{1}=0}^{r_{1}} \sum_{s_{2}=0}^{r_{2}} \ldots \sum_{s_{m}=0}^{r_{m}}(-1)^{A}\left(\begin{array}{l}
r_{1} \\
s_{1}
\end{array}\right)\left(\begin{array}{l}
r_{2} \\
s_{2}
\end{array}\right) \ldots\left(\begin{array}{l}
r_{m} \\
s_{m}
\end{array}\right) \times \frac{1}{\prod_{i=1}^{m-1} h\left(s_{i}\right)} \int_{0}^{\infty} t f(t) F^{B}(t) d t
$$

where $\mathrm{C}(\mathrm{r})=\prod_{j=1}^{m}\left(n-j+1-\sum_{k=0}^{j-1} r_{k}\right), \mathrm{A}=\sum_{i=1}^{m} s_{i}, h\left(s_{i}\right)=\sum_{i=1}^{m} s_{i}+i \quad$ and $\mathrm{B}=h\left(s_{m}\right)-1$.

In our case of exponentiated Weibull population, we get

$$
\begin{aligned}
& \mathrm{E}\left(T_{m} \mid R\right)=\mathrm{C}(\mathrm{r}) \Gamma\left(\frac{1}{\alpha}+1\right) \sum_{s_{1}=0}^{r_{1}} \sum_{s_{2}=0}^{r_{2}} \ldots \sum_{s_{m}=0}^{r_{m}}(-1)^{A}\left(\begin{array}{l}
r_{1} \\
s_{1}
\end{array}\right)\left(\begin{array}{l}
r_{2} \\
s_{2}
\end{array}\right) \ldots\left(\begin{array}{l}
r_{m} \\
s_{m}
\end{array}\right) \times \\
& \frac{1}{\prod_{i=1}^{m-1} h\left(s_{i}\right)} \sum_{i=0}^{\infty}(-1)^{i}\left(\begin{array}{c}
h\left(s_{m}\right) \theta-1 \\
i
\end{array}\right)(i+1)^{-\left(\frac{1}{\alpha}+1\right)} .
\end{aligned}
$$

When $r_{i}=0$ for all $i$ we have the case of a type-II censoring sampling test, and then $h\left(s_{i}\right)=i, h\left(s_{m}\right)=m$, $C(r) / \prod_{i=1}^{m-1} h\left(s_{i}\right)=m\left(\begin{array}{c}n \\ m\end{array}\right)$ and so the equation (19) reduces to equation (18).

For progressive type-II censoring with random removals, $\mathrm{R}$ terms are random. The expected test time, $E\left(T_{m}\right)$, to complete the experiment is given by taking the expectation of equation (19) with respect to $\mathrm{R}$. That is,

$$
E\left(T_{m}\right)=\mathrm{E}_{\mathrm{R}}\left[\mathrm{E}\left(T_{m} \mid \mathrm{R}\right)\right]=\sum_{\mathrm{r}_{1=0}}^{\mathrm{n}-\mathrm{m}} \sum_{\mathrm{r}_{2=0}}^{\mathrm{n}-\mathrm{m}-\mathrm{r}_{1}} \ldots \sum_{\mathrm{r}_{\mathrm{m}-1=0}}^{\mathrm{n}-\mathrm{m}-\mathrm{r}_{1}-\mathrm{r}_{2}-\cdots-\mathrm{r}_{\mathrm{m}-2}} \mathrm{E}\left[T_{m} \mid \mathrm{R}\right] \mathrm{P}(\mathrm{R}, \mathrm{p})
$$

where $\mathrm{P}(\mathrm{R}, \mathrm{p})$ is given by equation (9).

As a comparison scale, the ratio of the expected test times (RETT) can be computed between any two of progressive type II censoring with binomial removals, type II censoring, and complete sample by using the following ratios:

$$
\text { RETT1 }=\frac{E\left(T_{m}^{*}\right)}{E\left(T_{n}\right)}, \quad \text { RETT2 }=\frac{E\left(T_{m}\right)}{E\left(T_{n}\right)}, \quad \text { and } \quad \text { RETT3 }=\frac{E\left(T_{m}^{*}\right)}{E\left(T_{m}\right)} .
$$


These ratios are useful to compare the performance of the three types of sampling schemes. Practitioner may be of interest to compare the three expected times, $E\left(T_{n}\right), E\left(T_{m}^{*}\right)$ and $E\left(T_{m}\right)$, in order to determined whether the experiment time can be shortend significantly if a much lager sample of $\mathrm{n}$ test units is used. The test is stopped once $\mathrm{m}$ failures are occurred. To compare these three expected test times is analytically so difficult. A numerical study is conducted and the results are presented in the following section.

\section{Numerical Analysis}

Up to this point, we have derived the expected test time, $E\left(T_{m}\right)$, of progressively type II censored sample with binomial removals, $E\left(T_{m}^{*}\right)$ of type II censored sample, and $E\left(T_{n}\right)$, of complete sample. It will be of interest to compare these three expected test time, in order to gain some idea about the roles of $n, \quad m, \quad p, \alpha$, and $\theta$ on the duration of the lifetime test by numerically computing equations, (20), (18), (17) and the ratios in equation (21). As we discussed previously, different values of $\alpha$ and $\theta$ may result in different failure rates of the exponentiated Weibull distribution.Therefore, in this section, we choose (a) $\alpha=0.6$ and $\theta=2$, (b) $\alpha=5$ and $\theta=0.1$, (c) $\alpha=0.5$ and $\theta=0.5$, and (d) $\alpha=4$ and $\theta=0.6$ for numerical study.

For $n=8,10,12$, and 15 and $m=\mathrm{n} / 2, \mathrm{n} / 2+1, \ldots, n$, Figure 1 shows the ratio, RETT1, of the expected test time under type II censoring to the expected test time under complete sample. For fixed values of $\mathrm{m}$, the ratio decreases as $\mathrm{n}$ increases, but the size of decrement is influenced by the values of $\alpha$ and $\theta$. We also can find that the expected test time for type II censoring is lower than the half of expected test time for complete sample when the failure rate is unimodal or decreasing. If the failure rate is bathtub-shaped, the ratio is between 0.2 and 0.8 . For increasing failure rate, type II censoring scheme does not save too much experimental time comparing to complete sampling plan.

Figure 2 shows the ratio, RETT2, of the expected test time for progressive type II censoring with binomial removals and complete sample versus $n$ for $m=7$ and different values of removal probability $p$. The value of $p$ is an important factor on the expected test time. This is because small $p$, say $0.01,0.05$ or 0.10 , results in the later removals. The observed failures in a progressive type II censoring with binomial removals are almost the same as those in a type-II censoring. When $p$ is large, $n-m$ of the $n$ test units would be dropped out at the early stage of the life test such that the observed failure times are much closer to the tail of the lifetime distribution. Hence, the expected test time of progressive type-II censoring with binomial removals is close to that of complete sampling in which one observes $\mathrm{m}$ failures out of $\mathrm{m}$ test units. A larger value of $p$ always results in a longer duration of experimental time. The ratios under increasing failure rate are larger than those under the other three kinds of failure rate. For bathtub-shaped failure rate, the progressive type II censoring with binomial removals can save reasonable test time compared to the complete sample.

Tables 4 to 7 give the values of expected test time under progressive type II censoring with binomial removals for unimodal, bathtub-shaped, decreasing, and increasing failure rate, respectively. For $n=8,10,12$, and 15, the corresponding choices of $\mathrm{m}$ are listed in these tables. The case of $m=n$ corresponds to the complete sampling plans. Various values of removal probability $p$ are studied. In particular, $p=0.01,0.05,0.1,0.25$, and 0.5 are presented. Other values of $n, m$, and $p$ were also considered and the results are not reported here since they have similar patterns to the cases listed in these tables.

When $p$ is large, $n-m$ of the $n$ test units would be dropped out at the early stage of the life test. This results in the observed failure times much closer to the tail of the lifetime distribution, and hence the expected test time of progressive type II censoring with binomial removals is close to that of complete sample. In addition, when the shape of failure rate is unimodal, it usually takes a longer time to complete a progressively type II censored life test. However, when the failure rate is bathtub-shaped, the duration of the life test is usually short. For all values of $p$, the expected test time is decreasing when $\frac{m}{n}$ decreases.

Tables 4 to 7 also give the ratio, RETT3, of the expected test time for type II censoring and progressive type II censoring with binomial removals. When $p$ is large, the ratios show that type II censoring can save more experimental time than progressive type II censoring with binomial removals, especially for unimodal and decreasing failure rates. However, when $p$ is small, the durations of type II censoring and progressive type II censoring with binomial removals are almost the same. Note that the progressive type II censoring is desirable when a compromise between reduced time of experimentation and the observation of at least some extreme failure times is sought. The removal probability $p$ cannot be chosen too large. In practice, since the failure rate is usually bathtub-shaped or increasing, one might choose $p \leq 0.25$ based on Tables 5 and 7. Other values of $\alpha$ and $\theta$ were also considered and the results are not reported here since they have a similar pattern to the cases listed in Figures 1, 2 and Tables 4-7. 


\section{Conclusion}

In this study, we present some statistical inferences when the observed data are progressively type II censored with random removals. The results demonstrate that the classical point and interval estimations of shape parameters $\alpha$ and $\theta$ of the exponentiated Weibull model are most significant by the removal probability $p$. The significance is in terms of the reduction of RMSE, variance, the reduction of the width of CI and the satisfaction of coverage probability of the CIs. Although the CI based on the asymptotic distribution of the MLEs do not perform well for small sample size, the coverage probabilities improve to close the nominal level at suitable values of the removal probability $p$. However, increasing the removal probability $p$ produces censoring scheme as $R_{1}$ approaches $\mathrm{n}-\mathrm{m}$ and $R_{2}, R_{3}, \ldots, R_{m}$ approach zero. This choice of censoring scheme provides the smallest RMEs and variances for the estimates and improve the value of coverage probability of the CIs for all sample sizes. Balakrishnan et. al. (2003) reveals a similar result.

On the other hand, under profressively type II censored data with random removals, the required time to complete the test experiment increases significantly for various shapes of failure rates. The bathtub-shaped failure rate is of a shortest time of the test compared to other types of failure rates. However, in case of bathtub-shaped or increasing failure rate and the removal probability not too large, the test time can be reduced to that of type II censoring and the reduction is significant compared to complete sampling.

Table 4. Expected test time under progressive type II censoring with binomial removals and RETT3 when $\alpha=0.6$ and $\theta=2$

\begin{tabular}{|c|c|c|c|c|c|c|c|c|c|c|c|}
\hline \multirow[b]{3}{*}{$\mathrm{n}$} & \multirow[b]{3}{*}{$\mathrm{m}$} & \multicolumn{10}{|c|}{$p$} \\
\hline & & \multicolumn{2}{|c|}{0.01} & \multicolumn{2}{|c|}{0.05} & \multicolumn{2}{|c|}{0.1} & \multicolumn{2}{|c|}{0.25} & \multicolumn{2}{|c|}{0.5} \\
\hline & & $E\left(T_{m}\right)$ & RETT3 & $E\left(T_{m}\right)$ & RETT3 & $E\left(T_{m}\right)$ & RETT3 & $E\left(T_{m}\right)$ & RETT3 & $E\left(T_{m}\right)$ & RETT3 \\
\hline \multirow[t]{5}{*}{8} & 4 & 1.3415 & 0.9820 & 1.4482 & 0.9097 & 1.6087 & 0.8189 & 2.3001 & 0.5728 & 3.8292 & 0.3440 \\
\hline & 5 & 1.9794 & 0.9758 & 2.1956 & 0.8797 & 2.5203 & 0.7664 & 3.7049 & 0.5213 & 5.3594 & 0.3604 \\
\hline & 6 & 2.9273 & 0.9694 & 3.3223 & 0.8541 & 3.8539 & 0.7363 & 5.2911 & 0.5363 & 6.5586 & 0.4327 \\
\hline & 7 & 4.5490 & 0.9640 & 5.1344 & 0.8541 & 5.7280 & 0.7656 & 6.8337 & 0.6417 & 7.4715 & 0.5869 \\
\hline & 8 & 8.1840 & 1.0000 & 8.1840 & 1.0000 & 8.1840 & 1.0000 & 8.1840 & 1.0000 & 8.1840 & 1.0000 \\
\hline \multirow[t]{6}{*}{10} & 5 & 1.3668 & 0.9770 & 1.5090 & 0.8849 & 1.7304 & 0.7717 & 2.7443 & 0.4866 & 4.7837 & 0.2791 \\
\hline & 6 & 1.8749 & 0.9710 & 2.1246 & 0.8569 & 2.5181 & 0.7230 & 4.0668 & 0.4476 & 6.0713 & 0.2999 \\
\hline & 7 & 2.5664 & 0.9651 & 2.9803 & 0.8311 & 3.5991 & 0.6882 & 5.4821 & 0.4518 & 7.0715 & 0.3503 \\
\hline & 8 & 3.5835 & 0.9593 & 4.2240 & 0.8138 & 5.0375 & 0.6824 & 6.8315 & 0.5032 & 7.8522 & 0.4378 \\
\hline & 9 & 5.2995 & 0.9555 & 6.1051 & 0.8294 & 6.8547 & 0.7387 & 8.0183 & 0.6315 & 8.4818 & 0.5970 \\
\hline & 10 & 9.0093 & 1.0000 & 9.0093 & 1.0000 & 9.0093 & 1.0000 & 9.0093 & 1.0000 & 9.0093 & 1.0000 \\
\hline \multirow[t]{7}{*}{12} & 6 & 1.3863 & 0.9719 & 1.5650 & 0.8609 & 1.8528 & 0.7272 & 3.2352 & 0.4165 & 5.6668 & 0.2378 \\
\hline & 7 & 1.8096 & 0.9661 & 2.0954 & 0.8344 & 2.5633 & 0.6821 & 4.5015 & 0.3884 & 6.7390 & 0.2594 \\
\hline & 8 & 2.3546 & 0.9605 & 2.7938 & 0.8095 & 3.4950 & 0.6471 & 5.7970 & 0.3902 & 7.5790 & 0.2984 \\
\hline & 9 & 3.0911 & 0.9551 & 3.7426 & 0.7888 & 4.6851 & 0.6301 & 7.0079 & 0.4213 & 8.2523 & 0.3578 \\
\hline & 10 & 4.1660 & 0.9499 & 5.0716 & 0.7803 & 6.1431 & 0.6442 & 8.0713 & 0.4903 & 8.8110 & 0.4491 \\
\hline & 11 & 5.9584 & 0.9477 & 6.9741 & 0.8097 & 7.8407 & 0.7202 & 8.9695 & 0.6296 & 9.2902 & 0.6078 \\
\hline & 12 & 9.7125 & 1.0000 & 9.7125 & 1.0000 & 9.7125 & 1.0000 & 9.7125 & 1.0000 & 9.7125 & 1.0000 \\
\hline \multirow[t]{8}{*}{15} & 8 & 1.5716 & 0.9616 & 1.8576 & 0.8135 & 2.3465 & 0.6440 & 4.6460 & 0.3253 & 7.2381 & 0.2088 \\
\hline & 9 & 1.9460 & 0.9562 & 2.3569 & 0.7895 & 3.0649 & 0.6071 & 5.8300 & 0.3192 & 7.9693 & 0.2335 \\
\hline & 10 & 2.4090 & 0.9509 & 2.9861 & 0.7671 & 3.9536 & 0.5794 & 6.9390 & 0.3301 & 8.5698 & 0.2673 \\
\hline & 11 & 3.0006 & 0.9458 & 3.7945 & 0.7480 & 5.0223 & 0.5651 & 7.9254 & 0.3581 & 9.0788 & 0.3126 \\
\hline & 12 & 3.7938 & 0.9410 & 4.8528 & 0.7357 & 6.2609 & 0.5702 & 8.7746 & 0.4069 & 9.5227 & 0.3749 \\
\hline & 13 & 4.9412 & 0.9367 & 6.2572 & 0.7397 & 7.6384 & 0.6060 & 9.4932 & 0.4876 & 9.9186 & 0.4667 \\
\hline & 14 & 6.8244 & 0.9372 & 8.1291 & 0.7868 & 9.1064 & 0.7024 & 10.0976 & 0.6334 & 10.2777 & 0.6223 \\
\hline & 15 & 10.6077 & 1.0000 & 10.6077 & 1.0000 & 10.6077 & 1.0000 & 10.6077 & 1.0000 & 10.6077 & 1.0000 \\
\hline
\end{tabular}


Table 5. Expected test time under progressive type II censoring with binomial removals and RETT3 when $\alpha=5$ and $\theta=0.1$

\begin{tabular}{|c|c|c|c|c|c|c|c|c|c|c|c|}
\hline \multirow[b]{3}{*}{$\mathrm{n}$} & \multirow[b]{3}{*}{$\mathrm{m}$} & \multicolumn{10}{|c|}{$p$} \\
\hline & & \multicolumn{2}{|c|}{0.01} & \multicolumn{2}{|c|}{0.05} & \multicolumn{2}{|c|}{0.1} & \multicolumn{2}{|c|}{0.25} & \multicolumn{2}{|c|}{0.5} \\
\hline & & $E\left(T_{m}\right)$ & RETT3 & $E\left(T_{m}\right)$ & RETT3 & $E\left(T_{m}\right)$ & RETT3 & $E\left(T_{m}\right)$ & RETT3 & $E\left(T_{m}\right)$ & RETT3 \\
\hline \multirow[t]{5}{*}{8} & 4 & 0.2223 & 0.9802 & 0.2413 & 0.9030 & 0.2677 & 0.8140 & 0.3620 & 0.6019 & 0.5259 & 0.4143 \\
\hline & 5 & 0.3392 & 0.9785 & 0.3697 & 0.8978 & 0.4099 & 0.8097 & 0.5310 & 0.6250 & 0.6723 & 0.4937 \\
\hline & 6 & 0.4812 & 0.9798 & 0.5197 & 0.9073 & 0.5661 & 0.8329 & 0.6776 & 0.6958 & 0.7672 & 0.6146 \\
\hline & 7 & 0.6520 & 0.9847 & 0.6875 & 0.9338 & 0.7236 & 0.8872 & 0.7908 & 0.8118 & 0.8296 & 0.7739 \\
\hline & 8 & 0.8729 & 1.0000 & 0.8729 & 1.0000 & 0.8729 & 1.0000 & 0.8729 & 1.0000 & 0.8729 & 1.0000 \\
\hline \multirow[t]{6}{*}{10} & 5 & 0.2278 & 0.9732 & 0.2540 & 0.8728 & 0.2911 & 0.7616 & 0.4239 & 0.5230 & 0.6220 & 0.3564 \\
\hline & 6 & 0.3248 & 0.9720 & 0.3632 & 0.8692 & 0.4150 & 0.7607 & 0.5717 & 0.5522 & 0.7315 & 0.4316 \\
\hline & 7 & 0.4387 & 0.9736 & 0.4865 & 0.8779 & 0.5469 & 0.7809 & 0.6963 & 0.6134 & 0.8040 & 0.5312 \\
\hline & 8 & 0.5676 & 0.9764 & 0.6199 & 0.8940 & 0.6783 & 0.8170 & 0.7934 & 0.6985 & 0.8539 & 0.6490 \\
\hline & 9 & 0.7215 & 0.9825 & 0.7642 & 0.9276 & 0.8039 & 0.8818 & 0.8656 & 0.8190 & 0.8902 & 0.7963 \\
\hline & 10 & 0.9182 & 1.0000 & 0.9182 & 1.0000 & 0.9182 & 1.0000 & 0.9182 & 1.0000 & 0.9182 & 1.0000 \\
\hline \multirow[t]{7}{*}{12} & 6 & 0.2077 & 0.9437 & 0.2527 & 0.7756 & 0.3085 & 0.6353 & 0.4853 & 0.4039 & 0.6999 & 0.2800 \\
\hline & 7 & 0.3299 & 0.9739 & 0.3699 & 0.8686 & 0.4292 & 0.7486 & 0.6159 & 0.5217 & 0.7816 & 0.4111 \\
\hline & 8 & 0.4070 & 0.9658 & 0.4649 & 0.8456 & 0.5394 & 0.7288 & 0.7227 & 0.5439 & 0.8374 & 0.4694 \\
\hline & 9 & 0.5149 & 0.9691 & 0.5790 & 0.8618 & 0.6546 & 0.7623 & 0.8066 & 0.6186 & 0.8777 & 0.5685 \\
\hline & 10 & 0.6346 & 0.9735 & 0.6980 & 0.8851 & 0.7636 & 0.8091 & 0.8700 & 0.7101 & 0.9082 & 0.6802 \\
\hline & 11 & 0.7742 & 0.9809 & 0.8224 & 0.9234 & 0.8636 & 0.8793 & 0.9172 & 0.8280 & 0.9324 & 0.8145 \\
\hline & 12 & 0.9525 & 1.0000 & 0.9525 & 1.0000 & 0.9525 & 1.0000 & 0.9525 & 1.0000 & 0.9525 & 1.0000 \\
\hline \multirow[t]{8}{*}{15} & 8 & 0.2577 & 0.9480 & 0.3147 & 0.7763 & 0.3929 & 0.6218 & 0.6305 & 0.3875 & 0.8159 & 0.2994 \\
\hline & 9 & 0.3393 & 0.9540 & 0.4055 & 0.7983 & 0.4946 & 0.6545 & 0.7275 & 0.4449 & 0.8616 & 0.3757 \\
\hline & 10 & 0.4221 & 0.9576 & 0.4972 & 0.8130 & 0.5934 & 0.6812 & 0.8041 & 0.5027 & 0.8956 & 0.4513 \\
\hline & 11 & 0.5092 & 0.9607 & 0.5912 & 0.8275 & 0.6880 & 0.7110 & 0.8632 & 0.5667 & 0.9222 & 0.5305 \\
\hline & 12 & 0.6042 & 0.9643 & 0.6879 & 0.8469 & 0.7765 & 0.7503 & 0.9085 & 0.6413 & 0.9438 & 0.6173 \\
\hline & 13 & 0.7103 & 0.9699 & 0.7870 & 0.8753 & 0.8572 & 0.8037 & 0.9432 & 0.7304 & 0.9620 & 0.7161 \\
\hline & 14 & 0.8339 & 0.9787 & 0.8882 & 0.9188 & 0.9289 & 0.8786 & 0.9702 & 0.8412 & 0.9777 & 0.8347 \\
\hline & 15 & 0.9914 & 1.0000 & 0.9914 & 1.0000 & 0.9914 & 1.0000 & 0.9914 & 1.0000 & 0.9914 & 1.0000 \\
\hline
\end{tabular}


Table 6. Expected test time under progressive type II censoring with binomial removals and RETT3 when $\alpha=0.5$ and $\theta=0.5$

\begin{tabular}{|c|c|c|c|c|c|c|c|c|c|c|c|}
\hline \multirow[b]{3}{*}{$\mathrm{n}$} & \multirow[b]{3}{*}{$\mathrm{m}$} & \multicolumn{10}{|c|}{$p$} \\
\hline & & \multicolumn{2}{|c|}{0.01} & \multicolumn{2}{|c|}{0.05} & \multicolumn{2}{|c|}{0.1} & \multicolumn{2}{|c|}{0.25} & \multicolumn{2}{|c|}{0.5} \\
\hline & & $E\left(T_{m}\right)$ & RETT3 & $E\left(T_{m}\right)$ & RETT3 & $E\left(T_{m}\right)$ & RETT3 & $E\left(T_{m}\right)$ & RETT3 & $E\left(T_{m}\right)$ & RETT3 \\
\hline \multirow[t]{5}{*}{8} & 4 & 0.1296 & 0.9452 & 0.1644 & 0.7451 & 0.2284 & 0.5363 & 0.6161 & 0.1988 & 1.7475 & 0.0701 \\
\hline & 5 & 0.3201 & 0.9316 & 0.4325 & 0.6895 & 0.6346 & 0.4699 & 1.5395 & 0.1937 & 2.9926 & 0.0996 \\
\hline & 6 & 0.7643 & 0.9185 & 1.0694 & 0.6564 & 1.5227 & 0.4610 & 2.8556 & 0.2458 & 4.0980 & 0.1713 \\
\hline & 7 & 1.9196 & 0.9098 & 2.5386 & 0.6879 & 3.1664 & 0.5515 & 4.3358 & 0.4028 & 5.0103 & 0.3486 \\
\hline & 8 & 5.7639 & 1.0000 & 5.7639 & 1.0000 & 5.7639 & 1.0000 & 5.7639 & 1.0000 & 5.7639 & 1.0000 \\
\hline \multirow[t]{6}{*}{10} & 5 & 0.1243 & 0.9316 & 0.1678 & 0.6901 & 0.2544 & 0.4552 & 0.8577 & 0.1350 & 2.4936 & 0.0464 \\
\hline & 6 & 0.2643 & 0.9190 & 0.3782 & 0.6423 & 0.6053 & 0.4013 & 1.7952 & 0.1353 & 3.6291 & 0.0669 \\
\hline & 7 & 0.5433 & 0.9082 & 0.8115 & 0.6080 & 1.2911 & 0.3822 & 3.0060 & 0.1641 & 4.5974 & 0.1073 \\
\hline & 8 & 1.1268 & 0.8981 & 1.6885 & 0.5993 & 2.4701 & 0.4097 & 4.3126 & 0.2347 & 5.4035 & 0.1873 \\
\hline & 9 & 2.5127 & 0.8946 & 3.4171 & 0.6578 & 4.2585 & 0.5279 & 5.5647 & 0.4040 & 6.0850 & 0.3694 \\
\hline & 10 & 6.6772 & 1.0000 & 6.6772 & 1.0000 & 6.6772 & 1.0000 & 6.6772 & 1.0000 & 6.6772 & 1.0000 \\
\hline \multirow[t]{7}{*}{12} & 6 & 0.1208 & 0.9189 & 0.1736 & 0.6394 & 0.2864 & 0.3876 & 1.1645 & 0.0953 & 3.2541 & 0.0341 \\
\hline & 7 & 0.2312 & 0.9066 & 0.3505 & 0.5980 & 0.6092 & 0.3441 & 2.1310 & 0.0984 & 4.2637 & 0.0492 \\
\hline & 8 & 0.4291 & 0.8968 & 0.6795 & 0.5663 & 1.1879 & 0.3239 & 3.2830 & 0.1172 & 5.1134 & 0.0753 \\
\hline & 9 & 0.7921 & 0.8879 & 1.2827 & 0.5483 & 2.1234 & 0.3312 & 4.4788 & 0.1570 & 5.8308 & 0.1206 \\
\hline & 10 & 1.5019 & 0.8805 & 2.3706 & 0.5578 & 3.4882 & 0.3791 & 5.6109 & 0.2357 & 6.4500 & 0.2050 \\
\hline & 11 & 3.0867 & 0.8815 & 4.2791 & 0.6359 & 5.2965 & 0.5137 & 6.6216 & 0.4109 & 6.9981 & 0.3888 \\
\hline & 12 & 7.4939 & 1.0000 & 7.4939 & 1.0000 & 7.4939 & 1.0000 & 7.4939 & 1.0000 & 7.4939 & 1.0000 \\
\hline \multirow[t]{8}{*}{15} & 8 & 0.1548 & 0.8928 & 0.2499 & 0.5530 & 0.4795 & 0.2882 & 2.2352 & 0.0618 & 4.7593 & 0.0290 \\
\hline & 9 & 0.2612 & 0.8832 & 0.4416 & 0.5224 & 0.8743 & 0.2639 & 3.2981 & 0.0699 & 5.5228 & 0.0418 \\
\hline & 10 & 0.4330 & 0.8746 & 0.7596 & 0.4986 & 1.4914 & 0.2539 & 4.3936 & 0.0862 & 6.1777 & 0.0613 \\
\hline & 11 & 0.7145 & 0.8676 & 1.2810 & 0.4839 & 2.3806 & 0.2604 & 5.4389 & 0.1140 & 6.7524 & 0.0918 \\
\hline & 12 & 1.1940 & 0.8616 & 2.1244 & 0.4842 & 3.5648 & 0.2886 & 6.3880 & 0.1610 & 7.2678 & 0.1415 \\
\hline & 13 & 2.0731 & 0.8572 & 3.4615 & 0.5134 & 5.0304 & 0.3533 & 7.2246 & 0.2460 & 7.7384 & 0.2296 \\
\hline & 14 & 3.9104 & 0.8647 & 5.5212 & 0.6124 & 6.7278 & 0.5026 & 7.9517 & 0.4252 & 8.1740 & 0.4137 \\
\hline & 15 & 8.5814 & 1.0000 & 8.5814 & 1.0000 & 8.5814 & 1.0000 & 8.5814 & 1.0000 & 8.5814 & 1.0000 \\
\hline
\end{tabular}


Table 7. Expected test time under progressive type II censoringwith binomial removals and RETT3 when $\alpha=4$ and $\theta=0.6$

\begin{tabular}{|c|c|c|c|c|c|c|c|c|c|c|c|}
\hline \multirow[b]{3}{*}{$\mathrm{n}$} & \multirow[b]{3}{*}{$\mathrm{m}$} & \multicolumn{10}{|c|}{$p$} \\
\hline & & \multicolumn{2}{|c|}{0.01} & \multicolumn{2}{|c|}{0.05} & \multicolumn{2}{|c|}{0.1} & \multicolumn{2}{|c|}{0.25} & \multicolumn{2}{|c|}{0.5} \\
\hline & & $E\left(T_{m}\right)$ & RETT3 & $E\left(T_{m}\right)$ & RETT3 & $E\left(T_{m}\right)$ & RETT3 & $E\left(T_{m}\right)$ & RETT3 & $E\left(T_{m}\right)$ & RETT3 \\
\hline \multirow[t]{5}{*}{8} & 4 & 0.7384 & 0.9950 & 0.7538 & 0.9747 & 0.7745 & 0.9486 & 0.8441 & 0.8704 & 0.9588 & 0.7663 \\
\hline & 5 & 0.8350 & 0.9939 & 0.8560 & 0.9695 & 0.8834 & 0.9394 & 0.9649 & 0.8601 & 1.0592 & 0.7835 \\
\hline & 6 & 0.9337 & 0.9934 & 0.9589 & 0.9673 & 0.9893 & 0.9375 & 1.0629 & 0.8726 & 1.1225 & 0.8263 \\
\hline & 7 & 1.0448 & 0.9937 & 1.0687 & 0.9715 & 1.0929 & 0.9499 & 1.1380 & 0.9123 & 1.1640 & 0.8919 \\
\hline & 8 & 1.1930 & 1.0000 & 1.1930 & 1.0000 & 1.1930 & 1.0000 & 1.1930 & 1.0000 & 1.1930 & 1.0000 \\
\hline \multirow[t]{6}{*}{10} & 5 & 0.7492 & 0.9935 & 0.7698 & 0.9669 & 0.7978 & 0.9329 & 0.8915 & 0.8349 & 1.0255 & 0.7258 \\
\hline & 6 & 0.8274 & 0.9924 & 0.8538 & 0.9617 & 0.8888 & 0.9238 & 0.9929 & 0.8270 & 1.0988 & 0.7473 \\
\hline & 7 & 0.9064 & 0.9916 & 0.9377 & 0.9585 & 0.9771 & 0.9199 & 1.0754 & 0.8358 & 1.1469 & 0.7837 \\
\hline & 8 & 0.9910 & 0.9913 & 1.0248 & 0.9586 & 1.0631 & 0.9241 & 1.1396 & 0.8621 & 1.1802 & 0.8324 \\
\hline & 9 & 1.0895 & 0.9922 & 1.1187 & 0.9663 & 1.1458 & 0.9434 & 1.1879 & 0.9100 & 1.2047 & 0.8973 \\
\hline & 10 & 1.2238 & 1.0000 & 1.2238 & 1.0000 & 1.2238 & 1.0000 & 1.2238 & 1.0000 & 1.2238 & 1.0000 \\
\hline \multirow[t]{7}{*}{12} & 6 & 0.7569 & 0.9918 & 0.7829 & 0.9589 & 0.8182 & 0.9175 & 0.9354 & 0.8025 & 1.0778 & 0.6965 \\
\hline & 7 & 0.8227 & 0.9908 & 0.8545 & 0.9539 & 0.8970 & 0.9087 & 1.0223 & 0.7973 & 1.1320 & 0.7201 \\
\hline & 8 & 0.8888 & 0.9900 & 0.9258 & 0.9504 & 0.9734 & 0.9039 & 1.0929 & 0.8051 & 1.1692 & 0.7526 \\
\hline & 9 & 0.9577 & 0.9896 & 0.9986 & 0.9490 & 1.0475 & 0.9047 & 1.1482 & 0.8254 & 1.1962 & 0.7923 \\
\hline & 10 & 1.0334 & 0.9895 & 1.0749 & 0.9513 & 1.1186 & 0.9142 & 1.1907 & 0.8588 & 1.2169 & 0.8403 \\
\hline & 11 & 1.1235 & 0.9908 & 1.1570 & 0.9621 & 1.1857 & 0.9389 & 1.2230 & 0.9102 & 1.2336 & 0.9024 \\
\hline & 12 & 1.2476 & 1.0000 & 1.2476 & 1.0000 & 1.2476 & 1.0000 & 1.2476 & 1.0000 & 1.2476 & 1.0000 \\
\hline \multirow[t]{8}{*}{15} & 8 & 0.7920 & 0.9889 & 0.8290 & 0.9448 & 0.8794 & 0.8906 & 1.0327 & 0.7584 & 1.1549 & 0.6782 \\
\hline & 9 & 0.8451 & 0.9879 & 0.8878 & 0.9404 & 0.9448 & 0.8837 & 1.0959 & 0.7618 & 1.1853 & 0.7044 \\
\hline & 10 & 0.8988 & 0.9872 & 0.9466 & 0.9374 & 1.0081 & 0.8802 & 1.1464 & 0.7740 & 1.2083 & 0.7343 \\
\hline & 11 & 0.9545 & 0.9868 & 1.0063 & 0.9360 & 1.0689 & 0.8812 & 1.1860 & 0.7942 & 1.2265 & 0.7680 \\
\hline & 12 & 1.0142 & 0.9866 & 1.0680 & 0.9369 & 1.1267 & 0.8881 & 1.2169 & 0.8223 & 1.2415 & 0.8060 \\
\hline & 13 & 1.0812 & 0.9871 & 1.1326 & 0.9423 & 1.1808 & 0.9039 & 1.2410 & 0.8600 & 1.2542 & 0.8510 \\
\hline & 14 & 1.1625 & 0.9890 & 1.2013 & 0.9570 & 1.2304 & 0.9344 & 1.2600 & 0.9125 & 1.2653 & 0.9086 \\
\hline & 15 & 1.2751 & 1.0000 & 1.2751 & 1.0000 & 1.2751 & 1.0000 & 1.2751 & 1.0000 & 1.2751 & 1.0000 \\
\hline
\end{tabular}


(a) $\alpha=0.6 \quad \theta=2$

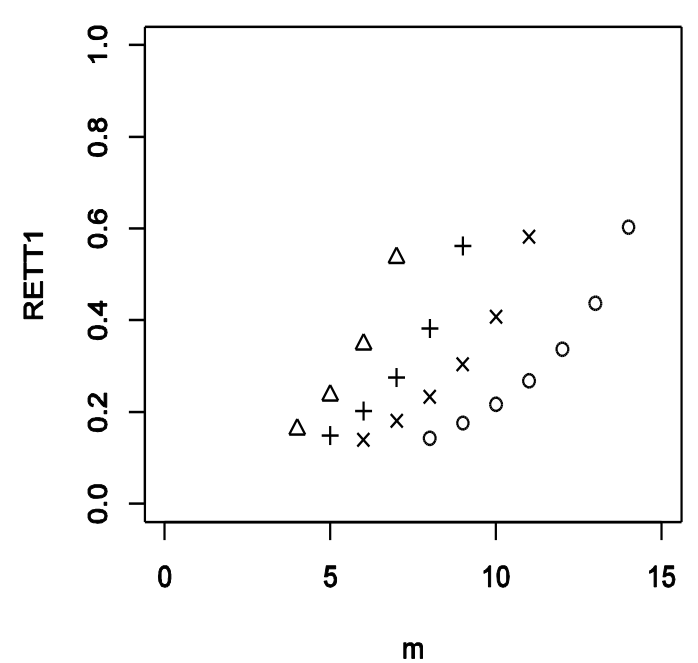

(c) $\alpha=0.5 \quad \theta=0.5$

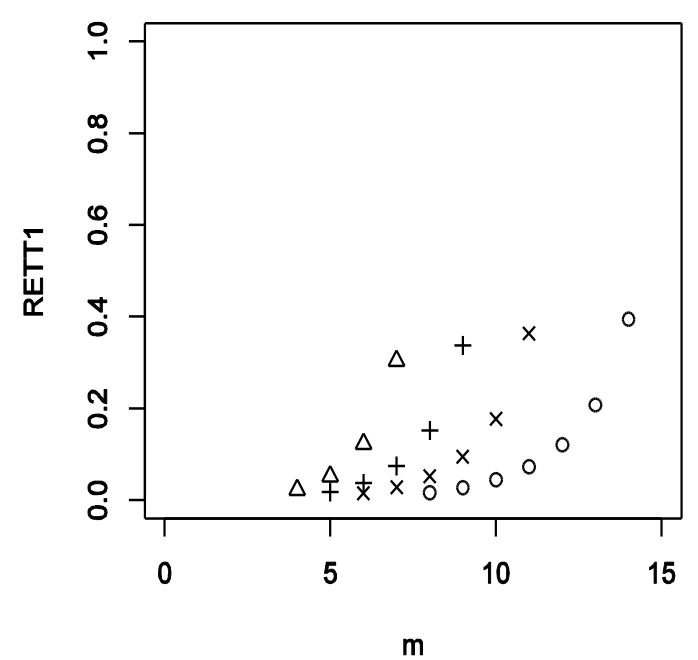

(b) $\alpha=5 \quad \theta=0.1$

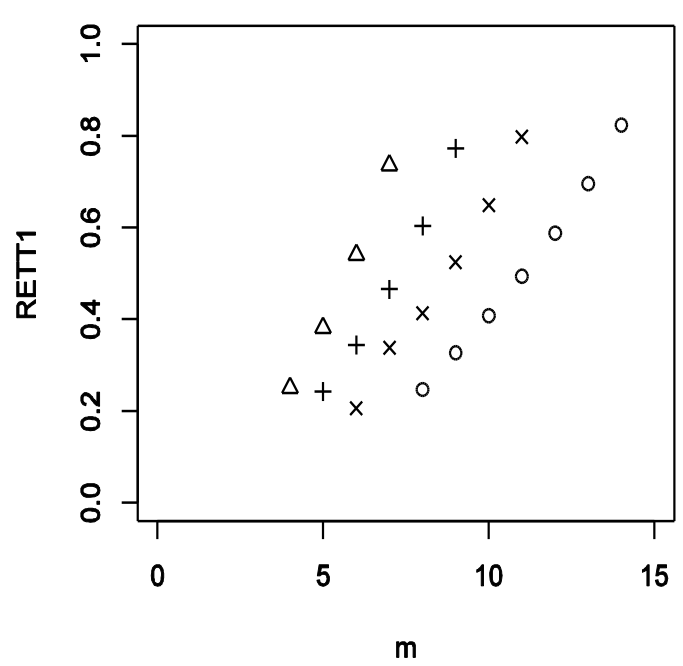

(d) $\alpha=4 \quad \theta=0.6$

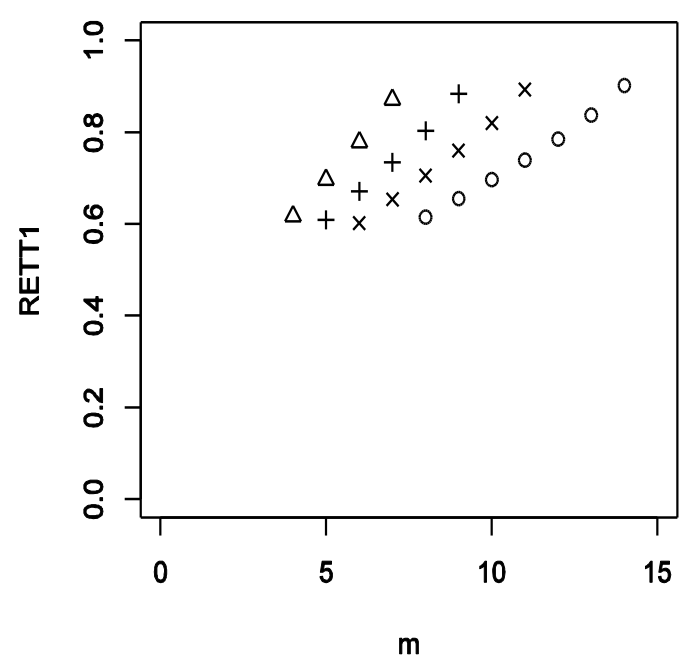

Figure 1. Ratio of expected test time under type II censoring to that under complete sample. $n=8, \triangle ; n=10,+$; $n=12, \times ; n=15$, 。 
(a) $\alpha=0.6 \quad \theta=2$

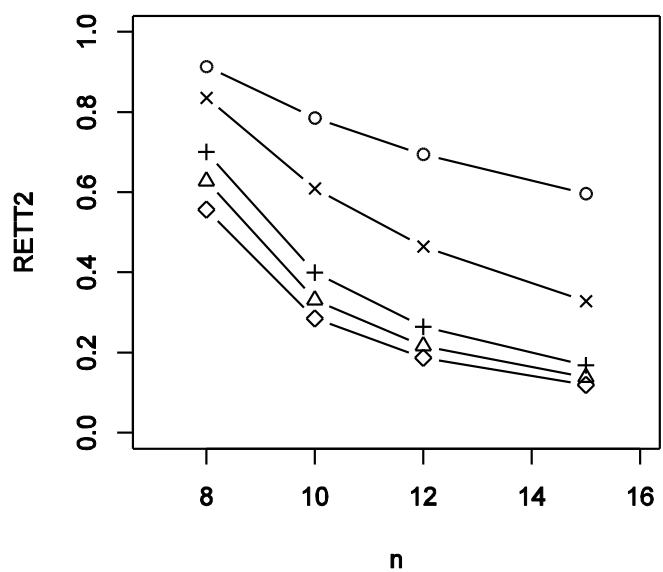

(c) $\alpha=0.5 \quad \theta=0.5$

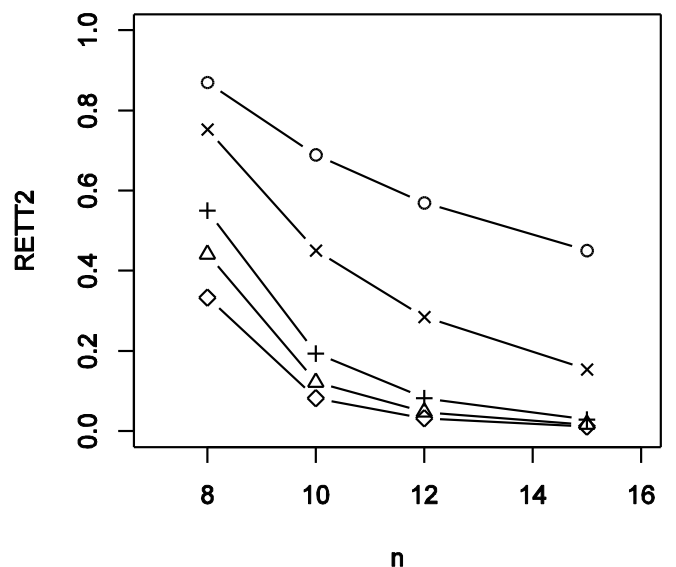

(b) $\alpha=5 \quad \theta=0.1$

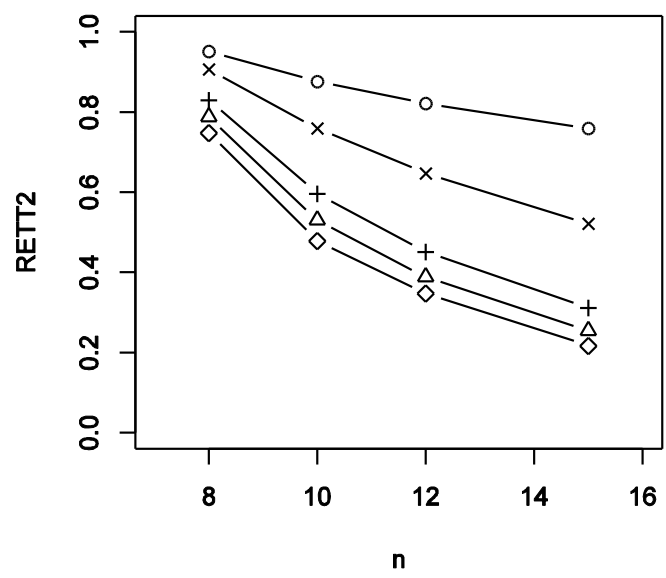

(d) $\alpha=4 \quad \theta=0.6$

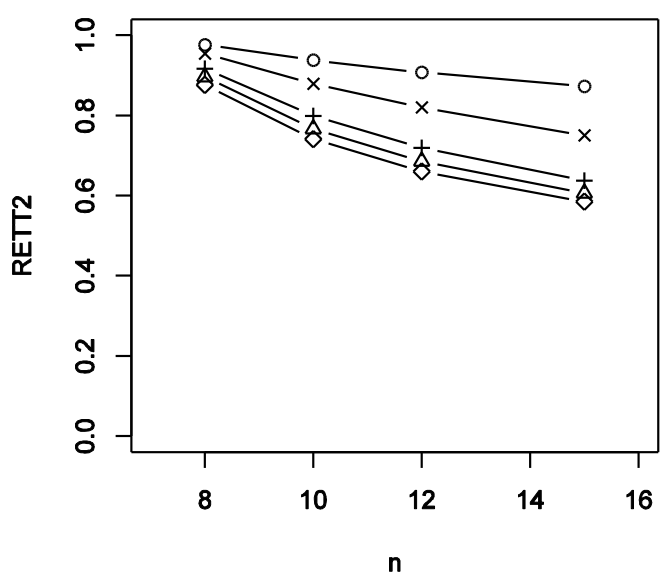

Figure 2. Ratio of expected test time under progressive type II censoring with binomial removals to that under complete sample. $p=0.01, \diamond ; p=0.05, \triangle ; p=0.10,+; p=0.25, \times ; p=0.50, . \circ ; \mathrm{m}=7$

\section{Acknowledgement}

This paper was funded by Deanship of Scientfic Researsh (DSR), King Abdulaziz University, Jeddah, under grant no. (G: 13-266-D32). The authors acknowledge thanks DSR financial support. The Authors are also grateful to Syuan-Rong Huang (Department of Statistics, Tamkang University, Taiwan) for his valuable efforts in running the computations of the results.

\section{References}

Balakrishnan, N., \& Aggarwala, R. (2000). Progressive censoring: Theorey, Methods, and Applications. Brikhauser, Boston. ISBN 978-1-4612-1334-5. https://doi.org/10.1007/978-1-4612-1334-5

Balakrishnan, N., \& Sandhu, R. A. (1995). A simple simulational algorithm for generating progressive type II censored samples. American Statistician, 49, 229-230. https://doi.org/10.2307/2684646

Balakrishnan, N., Kannan, N., Lin, C. T., \& Ng, H. K. (2003). Point and interval estimation for Gaussian distribution based on proressively type II censored samples. IEEE Transations on Reliability, 52, 90-95. https://doi.org/10.1109/TR.2002.805786

Basak, P., Basak, I., \& Balakrishnan, N. (2009). Estimation for the three-parameter lognormal distribution based on proressively censored data. Computational Statistics \& Data Analysis, 53, 3580-3592. https://doi.org/10.1016/j.csda.2009.03.015 
Cheng, C., Chen, J., \& Li, Z. (2010). A new algorithm for maximum likelihood estimation with progresssive type II interval censored data. Communications in Statistics-Simulation and Computation, 39, 750-766. https://doi.org/10.1080/03610911003637406

Childs, A., \& Balakrishnan, N. (2000). Conditional inference procedures for the Laplace distribution when the observed samples are progressively censored. Metrika, 52, 253-265. https://doi.org/10.1007/s001840000092

Cohen, A. C. (1963). Progressively censored samples in life testing. Technometrics, 5, 327-339. https://doi: $10.2307 / 1266337$

Kim, C., Jung, J., \& Chung, Y. (2011). Bayesian estimation for the exponentiated Wiebull model under type II progressive censoring. Stat Papers, 52, 53-70. https://doi.org/10.1007/s00362-009-0203-2

Kumar, M., Singh, S. K., \& Singh, U. (2019). Reliability estimation for poisson-exponential model under progressive type II censoring data with binomial removal data. Statistica, 76(1), 3-26. https://doi.org/10.6092/issn.1973-2201/5457

Madi, M. T., \& Raqab, M. Z. (2009). Bayesian inference for the generalized exponential distribution based on progressively censored data. Communications in Statistics-Theory and Methods, 38, 2016-2029. https://doi.org/10.1080/03610920902855951

Makelainen, T., Schmidt, K., \& Styan, G. P. H. (1981). On the existence and uniqueness of the maximum likelihood estimate of a vector-valued parameter in fixed-size samples. The Annals of Statistics, 9(4), 758-767. https://doi.org/10.1155/2009/310575

Mood, A. M., Graybill, F. A., \& Boes, D. C. (1974). Introduction to the Theory of Statistics. 3rd edition McGraw-Hill, Kogkusha Ltd. ISBN-13: 978-0070428645

Mousa, M., \& Jaheen, Z. (2002). Statistical inference for the Burr model based on progressively censored data. An International Computers \& Mathematics with Applications, 43, 1441-1449. https://doi.org/10.1016/S0898-1221(02)00110-4

Mudholkar, G. S., \& Hutson, A. D. (1996). The exponentiated Weibull family: Some properties and aflood data application. Communications in Statistics - Theory and Methods, 25, 3059-3083. https://doi.org/10.1080/03610929608831886

Mudholkar, G. S., Srivastava, D. K., \& Freimer, M. (1995). The exponentiated Weibull family: A reanalysis of the bus-motor-failure data. Technometrics, 37, 436-445. https://doi.org/10.2307/1269735

Nassar, M. M., \& Eissa, F. H. (2003). On the exponentiated Weibull distribution. Communications in Statistics - Theory and Methods, 32, 1317-1336. https://doi.org/10.1081/STA-120021561

Ng, H. K. T., Kundu, D., \& Chan, P. S. (2009). Statistical analysis of exponential lifetimes under an adaptive type-II progressive censoring scheme. Naval Research Logistics, 56, 687-698. https://doi.org/10.1002/nav.20371

Rao, C. R. (1973). Linear Statistical Inference and Its Applications. 2nd edition, Johnson Willy \& Sons, New York. https://doi.org/10.1002/9780470316436

Sarhan, A. M., Alameri, M., \& Al-Wasel, I. (2008). Analysis of proressive censoring competing risks data with binomial removals. International Journal of Mathemtical analysis, 2, 965-997

Soliman, A. (2005). Estimation of parameters of life from progressive censored data using Burr-XII model. IEEE Transactions on Reliability, 54, 34-42. https://doi.org/10.1109/TR.2004.842528

Stewart, J. (2008). Calculus Early Transcendentals. Sixth Edition, Thomson Books/cole, USA. ISBN-13: 9780495011668

Tse, S.-K., Yang, C., \& Yuen, H.-K. (2000). Statistical Analysis of Weibull distributed lifetime data under type II progressive censoring with binomial removals. Journal of Applied Statistics, 27, 1033-1043. https://doi.org/10.1080/02664760050173355

Viveros, R., \& Balakrishnan, N. (1994). Interval estimation of parameters of life from progressively censored data. Technometrics, 36, 84-91. https://doi.org/10.2307/1269201

Wu, S.-J., \& Chang, C.-T. (2003). Inference in the Pareto distribution based on progressive type II censoring with random removals. Journal of Applied Statistics, 30, 163-172. https://doi.org/10.1080/0266476022000023721

Wu, S.-J., Chen, Y. J., \& Chang, C.-T. (2007). Statistical inference based on progressively censored samples with random removals from Burr type XII distribution. Journal of Statistical Computation and Simulation, 77, 19-27. https://doi.org/10.1080/10629360600569204 
Yuen, H.-K., \& Tse, S.-K. (1996). Parameters estimation for Weibull distributed lifetimes under progressive censoring with random removals. Journal of Statistical Computation and Simulation, 55, 57-71. https://doi.org/10.1080/00949659608811749

\section{Copyrights}

Copyright for this article is retained by the author(s), with first publication rights granted to the journal.

This is an open-access article distributed under the terms and conditions of the Creative Commons Attribution license (http://creativecommons.org/licenses/by/4.0/). 